\title{
Evaluation of Outcome of ORIF by DCP Vs LCP in Mid-Shaft Fractures of Radius - Ulna in A Secondary Level Hospital of Bangladesh
}

\author{
Rahman MA ${ }^{1}$, Kaiser MS ${ }^{2}$, Alam SMSU $^{3}$
}

Conflict of Interest: None Received: 12.05 .2019

Accepted: 08.10 .2019

www.banglajol.info/index.php/JSSMC

Key Words:

Mid-shaft fractures; radius and ulna; LCP vs. DCP.

\begin{abstract}
Purpose: To compare the result of mid-shaft fracture radius and ulna treated by small DCP and LCP.

Methods: Prospective interventional study, done in the Department of Orthopaedic Surgery, 250 Bedded General Hospital, Tangail from January, 2017 to December, 2018. The study was carried out with sample size 30 patients of mid-shaft fracture of radius and ulna. Out of them 15 were treated by DCP and screws and 15 patients were treated by LCP and screws.

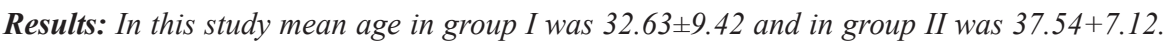
Male patients were 17 and female were 13 in number. Motor vehicle accident was the commonest cause of fracture found in $60 \%$ in group-I and $73.33 \%$ in group-II. In group-I, out of 15 cases all cases (100\%) united with mean time of $15.87 \pm 3.89$ weeks. In group-II, out of 15 cases all $(100 \%)$ cases united with the mean time of $14.0 \pm 2.27$ weeks. There was no major complication in both groups. Regarding the final outcome, excellent results in group-I were achieved with $11(73.33 \%)$ cases while in group-II with $12(80.00 \%)$ cases. Satisfactory results were seen in 04 (26.67\%) cases in group-I and 03 (20.00\%) cases in group-II.
\end{abstract}

Conclusion: On the statistical point of view there was no significant difference between dynamic compression plate group and locking compression plate group for the treatment of mid-shaft fracture radius and ulna.

[J Shaheed Suhrawardy Med Coll 2019; 11(2): 106-109] DOI: https://doi.org/10.3329/jssmc.v11i2.48959

\section{Introduction}

Diaphyseal fractures of the radius and ulna present specific problems not encountered in the treatment of fractures of the shafts of other long bones. In addition to restoration of length, apposition and normal axial alignment, correct rotational alignment must also be achieved if a good range of pronation and supination is to be restored. Furthermore, there is a high incidence of malunion and nonunion because it is difficult to reduce and maintain the reduction of two mobile parallel bones in the presence of the pronating and supinating muscles which exert angulatory as well as rotational forces. Malunion, especially shortening and angulation of the radius or ulna, may cause functional

1. Dr. Md. Asjadur Rahman, Asst. Professor, Department of Orthopaedics, Sheikh Hasina Medical College, Tangail

2. Dr. Md. Shahidullah Kaiser, Associate Professor and Head, Department of Orthopaedics, Sheikh Hasina Medical College, Tangail

3. Dr. S.M. Syeed-Ul-Alam, Associate Surgeon, Department of Surgery, Shaheed Suhrawardy Medical College \& Hospital, Dhaka

Correspondence: Dr. Md. Asjadur Rahman, Asst. Professor, Department of Orthopaedics, Sheikh Hasina Medical College, Tangail Phone: 01715312987, E-mail:dra.rahman73@gmail.com problems at the wrist or elbow and impair the normal hand function. ${ }^{1,2}$ Among various modalities of surgical treatment dynamic compression plate fixation remains the gold standard. In selected patient of radius-ulna fractures it is preferred method because of its high success rate. It is known that anatomical reduction and rigid fixation in an attempt to achieve primary bone-healing may delay union as a result of excessive soft-tissue and periosteal stripping. ${ }^{3-6}$ Hence, over the past decade, there has been an increasing emphasis on the concept of "biological fixation" for the treatment of long-bone fractures. This observation prompted the development of the locking pate which decreases the bone-contact area. ${ }^{7,8}$ This locking minimizes the compressive forces exerted by the plate on the bone. Locking compression plate (LCP) is another effective bridging device used for treating comminuted fracture. But for treating simple fractures, its superiority over conventional plating yet to be proven. Locking plates may give improved fixation in osteoporotic bone and results in less plate-induced osteoporosis and lower 
infection rates. The purpose of the present study was to test the hypothesis that use of the LCP device for the treatment of mid-shaft fractures of the forearm results in better bone-healing and decreased complications as compared with use of the DCP device. ${ }^{9-10}$ This study includes those patients who reported Orthopaedic Department, 250 Bedded General Hospital, Tangail after initial injuries to the forearms with the complain of instability, abnormal mobility in forearm, pain to the fracture site and impaired function of the limb.

\section{Materials and Method}

During the period of January, 2017 to December, 2018, a randomized comparative study was carried out at 250 Bedded General Hospital, Tangail to evaluate the operative management of closed mid-shaft fracture radius and ulna; fixation by small DCP and fixation by LCP. A total of 30 consecutive cases of closed mid-shaft fracture radius and ulna were enrolled by two groups (each group consists of 15 cases) in this study. All cases of odd numbers were placed in group-I (fixation done by DCP) and all cases of even numbers were placed in group-II (fixation done by LCP). Every case was assessed clinically and radiologically.

\section{Operative technique}

All the patients were operated under general anaesthesia in supine position. A tourniquet was used. Anterior Henry

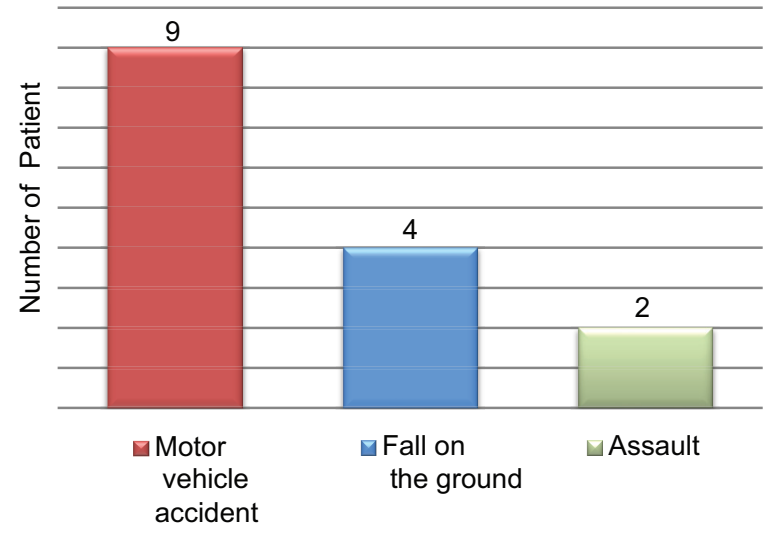

approach was carried out for radius and posterior approach for ulna. Fracture site was then exposed and was reduced. DCP or Locking plate and screws were applied on anterior surface of radius and on posterior surface of ulna, centering the fracture site.

The wounds were closed in layers after maintaining the haemostasis. A drain was kept in situ on radial side. Dressing with long arm back slab was given.

\section{Post-operative management}

Drain was removed on $2^{\text {nd }}$ post operative day, stitches after 14 days. Finger and shoulder movement was started on $1^{\text {st }}$ post operative day. Back slab was removed after six weeks.

\section{Result}

In this study mean age in group I was $32.63 \pm 9.42$ and in group II was $37.54+7.12$. Male patients were 17 and female were 13 in number. Motor vehicle accident was the commonest cause of fracture found in $60 \%$ in group-I and $73.33 \%$ in group-II.

In this series, in group-I the time elapsed between injury and surgery was minimum and maximum of 04 weeks and 48 weeks respectively with a mean of $12.49 \pm 13.15$, while in group-II minimum and maximum of 05 weeks and 52 weeks respectively with a mean of $14.57 \pm 13.81$ weeks.

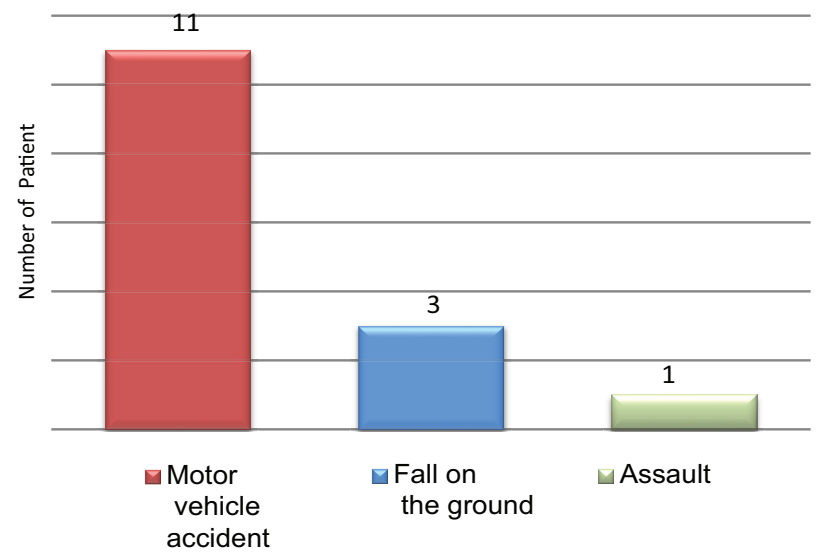

Fig.-1: Distribution of patients according to cause of injury $(n=30)$.

\section{Table-I}

Distribution of patients according to time taken for union $(n=30)$.

\begin{tabular}{lcccccc} 
Treatment method & No. of cases & \multicolumn{2}{c}{ Time taken for union (in weeks) } & Mean ( \pm SD) & tValue & $p$ Value \\
& & Minimum & Maximum & (in weeks) & 1.61 & 0.05 \\
Group-I & 15 & 12 & 24 & $15.87 \pm 3.89$ & $14.0 \pm 2.27$ & \\
Group-II & 15 & 10 & 18 & 14 & \\
\hline
\end{tabular}

Statistical analysis was done by unpaired t-test, Group-I $=$ DCP and Group-II $=$ LCP, $p>0.05$ indicates non significant $\mathrm{n}=$ Number of cases 


\section{Table-II}

Comparison of functional outcome between two groups after 6 months $(n=30)$ by Anderson et al. criteria.

\begin{tabular}{lccccc}
\hline Functional outcome & \multicolumn{2}{c}{ Group-I $(\mathrm{n}=15)$} & & \multicolumn{2}{c}{ Group-II $(\mathrm{n}=15)$} \\
\cline { 2 - 3 } \cline { 5 - 6 } & No. of patients & Percentage & & No. of patients & Percentage \\
\hline Excellent & 11 & 73.33 & & 12 & 80 \\
Satisfactory & 4 & 26.67 & & 3 & 20 \\
Unsatisfactory & 0 & 0 & & 0 & 0 \\
Failure & 0 & 0 & & 0 & 0 \\
$p$ value & & & 0.67 & & \\
\hline
\end{tabular}

Statistical analysis was done by unpaired t-test, Group-I = DCP and Group-II $=\mathrm{LCP}, p>0.05$ indicates non significant $\mathrm{n}=$ Number of cases

In group-I, out of 15 cases all cases (100\%) united with mean time of $15.87 \pm 3.89$ weeks. In group-II, out of 15 cases all $(100 \%)$ cases united with the mean time of 14.0 \pm 2.27 weeks.

There was no major complication in both groups. Regarding the final outcome, excellent results in group-I were achieved with $11(73.33 \%)$ cases while in group-II with $12(80.00 \%)$ cases. Satisfactory results were seen in $04(26.67 \%)$ cases in group-I and $03(20.00 \%)$ cases in group-II.

\section{Discussion}

This study was carried out at 250 Bedded General Hospital, Tangail from January, 2017 to December, 2018 to compare the outcome of the results of internal fixation of mid-shaft fracture radius and ulna by DCP and screws (Group-I) and LCP and screws (Group-II). A total number of 30 patients were included in this study, 15 patients were treated by dynamic compression plate and screws and 15 patients were treated by locking compression plate and screws. Minimum follow up time was 6 months and maximum 18 months.

In this study mean age was $32.63 \pm 9.42$ years in group-I and $37.54 \pm 7.12$ years in group-II. These figures were compared favorably with other workers. The high incidence of young adult age group points to the higher rate of mobility as well as social violence age group. Eight $(53.33 \%)$ cases were male and $07(46.67 \%)$ cases were female in group-I and $09(60.00 \%)$ cases were male and $06(40.00 \%)$ cases were female in group-II. Males being the major working force of our society and thus more consistently exposed to the external environment, which probably accounts for this predominance.

Exploration of occupation in this series demonstrated that $02(13.33 \%)$ labours followed by 01 (6.67\%) businessmen,
$02(13.33 \%)$ farmers, 05 (33.33\%) housewives, 02 $(13.33 \%)$ service holders and $03(20.00 \%)$ students in group-I, and 01 (6.67\%) labours followed by $02(13.33 \%)$ businessmen, 02 (13.33\%) farmers, 04 (26.67\%) housewives, 04 (26.67\%) service holders and $02(13.33 \%)$ students in group-II.

In this study motor vehicle accidents were found to be the most common causative factor of the injury accounting $09(60 \%)$ in group-I and $11(73.33 \%)$ in group-II. Right side involvement was seen in $06(40 \%)$ cases and left side $09(60.00 \%)$ cases in group-I, while right side involvement was seen in 07 (46.67\%) cases and left side 08 (53.33\%) cases in group-II.

In group-I out of 15 cases of mid-shaft fracture radius and ulna, both clinically and radiologically all cases were found to unite. The union rate was $100 \%$. In group-II, all of 16 cases of mid-shaft fracture radius and ulna both clinically and radiologically were found to unite. The union rate was $100 \%$. In group-I, in this study mean union time was $15.87 \pm 3.89$ weeks with minimum 12 weeks and maximum 24 weeks. And in group-II, mean union time was $14.00 \pm$ 2.27 weeks with minimum 10 weeks and maximum of 18 weeks. In the study there was no significant difference between two groups in relation to both duration of injury and time taken for union.

In this study, there was $13.33 \%$ infection in group-I. It was superficial and was controlled by dressing and antibiotic. In group-II, there was no infection during follow up period. According to Anderson et al. criteria, in groupI, $11(73.33 \%)$ cases had excellent and $04(26.67 \%)$ cases had satisfactory outcome. In group-II, 12 (80\%) cases had excellent functional outcome and $03(20 \%)$ cases had satisfactory outcome.

There are two international comparative study of fixation fractures radius and ulna by DCP and LCP. One was done 
in Mexico in 2007 by Martinez-Padilla LA and PenafortGarcia JA, and the other was done by Stevens CT and Ten Duis HJ in Belgium in 2008. They have 22 and 10 patients in DCP group, and 11 and 09 patients in LCP group respectively. ${ }^{11,12}$

Martinez and Penafort, 2007 observed a male predominance of $88 \%$. They had union rate of $100 \%$ in both DCP and LCP group. In their study 19 (86.30\%) cases had excellent functional outcome and 03 (13.7\%) cases had satisfactory in group-I, while $10(89.90 \%)$ cases had excellent functional outcome and $01(9.10 \%)$ cases had satisfactory in group-II.

Stevens CT and Ten Duis, 2008 observed motor vehicle accidents as the major reason for forearm fractures occupying $50 \%$. They found $66.76 \%$ of the cases with left forearm fracture. In their study, mean union time was 22 weeks in DCP group and 33 weeks in LCP group. Stevens CT and Ten Duis HJ, 2008 reported no infection in both group.

In this study, statistical result showed that there was no significant difference in functional outcome between two groups ( $p>0.05)$. A larger randomized multicenter trial can further improve the interpretation of the results.

\section{Conclusion}

Statistically overall result was shown that there was no significant difference between group-I (DCP) and groupII (LCP). So, it is concluded that mid-shaft fracture radius and ulna can be treated by either dynamic compression plate and screws or with locking compression plate and screws.

\section{References}

1. Jinkins W J, JR, Lockhart L D and Eggers G W N, 1960. Fractures of Forearm in Adults. Southern Med. J., vol. 53-A, pp. 669-79.

2. Caden J G, 1961. Internal Fixation of Fractures of the Forearm. J. Bone and Joint Surg., vol. 43-A, pp. 1115-21.

3. Anderson LD, Sisk TD, Tooms RE and Park WI, 1975. Compression-plate fixation in acute diaphyseal fractures of the radius and ulna. J. Bone Joint Surg., vol. 57-A, pp. 287-89.

4. Dodge HS and Cady G W, 1972. Treatment of Fractures of the Radius and Ulna with Compression Plates: A Retrospective Study of One Hundred and Nineteen Fractures in Seventy-eight Patients. J. Bone and Joint Surg., vol. 54-A, pp. 1167-76.

5. Kaleta M, Malecki P, Tokarowski A and Kusz D, 1995. Treatment Outcome for Forearm Shaft Fracture Using AO Plate Stabilization. Chir-Narzadow-Ruchu-Orthop-Pol., vol. 60(4), pp. 257-63.

6. Müller M E, Allgower M, Schneider R and Willenegger H, 1979. Manual of Internal Fixation. Techniques Recommended by the AO Group. Ed. 2.

7. Schatzker J, 1995. Changes in the AO/ASIF principles and methods. Injury, vol.26, pp. 51-56.

8. Larson AN, Rizzo M, 2007. Locking Plate Technology and Its Applications in Upper Extemity Fracture Care. hand Clin, vol. 23(2), pp.269-78.

9. Leung F and Chow SP, 2006. Locking compression plate in the treatment of forearm fractures: a prospective study. Journal of Orthopaedic Surgery, vol. 14, pp. 291-94.

10. Niemeyer P, Sudkamp NP, 2006. Principles and Clinical Application of the Locking Compression Plate (LCP). Acta Chirurgiae Orthopaedicae, vol.73, pp. 221-28.

11. Martinez-Padilla LA and Penafort-Garcia JA, 2007. Radiographic and functional results of plate of oxnamic ram compression versus plate of compression bolted in radial and cubital fractures. Acta Orthop Mex, vol. 21(6), pp. 304-12.

12. Stevens CT and Ten Duis HJ, 2008. Plate osteosynthesis of simple forearm fractures: LCP versus DC plates. Acta Orthop. Belg, vol.74, pp. 180-83. 